\title{
A CRIANÇA EM PROCESSO DE APRENDIZAGEM DA LIBRAS: nas sutilezas do ato de inclusão escolar
}

\author{
Children in the learning process of Libras: in the subtleties of the act of school \\ inclusion
}

\author{
Maria Helena de Oliveira ${ }^{1}$ \\ Francisco Renato Lima ${ }^{2}$
}

RESUMO: A Libras é a Língua Brasileira de Sinais desenvolvida e utilizada por comunidades de surdos. Essa língua tem como canal de comunicação, movimentos e expressões que são percebidos pela visão. Desse modo, neste artigo, tivemos como objetivo analisar o processo da apropriação da Libras por uma criança com deficiência auditiva, observando sua capacidade de aprendizagem e em que medida essa aprendizagem favorecerá no seu desenvolvimento social e pessoal. Teoricamente, partimos de uma pesquisa bibliográfica, em teóricos como: Castro; Carvalho (2005), Goldfeld (1997), Oliveira (2002), Quadros (1997), Silva (2001), entre outros. E também, pesquisa de campo, quando realizamos um estudo de caso, por meio do acompanhamento do processo ensino e aprendizagem da Libras por uma aluna surda, levando em consideração todos os aspectos que envolveram a vida do sujeito. Os resultados obtidos demonstram que a criança tem um bom desenvolvimento intelectual e facilidade de assimilação e compreensão das Libras. Através deste trabalho, percebemos a importância do ensino de Libras nas escolas como primeira língua dos surdos, confirmando que, quanto mais cedo as crianças tiverem acesso a esse aprendizado, melhor será o seu desenvolvimento.

Palavras-chave: Comunicação. Deficiência auditiva. Processo de ensino e aprendizagem. Libras.

ABSTRACT: Libras is the Brazilian Sign Language developed and used by communities of the deaf. This language has as communication channel, movements and expressions that are perceived by the vision. Thus, in this article, we aimed to analyze the process of appropriation of Libras by a hearing impaired child, observing their ability to learn and to what extent this learning will favor their social and

\footnotetext{
${ }^{1}$ Graduada em Letras - Português (UESPI). Especialista em Docência do Ensino Superior (FAERPI). Especialista em LIBRAS: Língua Brasileira de Sinais (IFPI). Mestre em Letras Estudos da Linguagem (UFPI). Professora de Língua Portuguesa na Secretaria Estadual de Educação e Cultura (SEDUC-PI). E-mail: revisora helena@hotmail.com
${ }^{2}$ Mestre em Letras - Estudos da Linguagem (UFPI). Professor Substituto (Auxiliar Nível - I) da Universidade Federal do Piauí, lotado no Departamento de Métodos e Técnicas de Ensino (DMTE). Coordenador de disciplinas do Centro de Educação Aberta e a Distância (CEAD/UFPI). E-mail: fcorenatolima@hotmail.com


personal development. Theoretically, we start from a bibliographical research, in theorists as: Castro; Carvalho (2005), Goldfeld (1997), Oliveira (2002), Quadros (1997), Silva (2001), among others. Also, field research, when we carried out a case study, through the accompaniment of the teaching and learning process of Libras by a deaf student, taking into account all the aspects that involved the life of the subject. The results show that the child has a good intellectual development and ease of assimilation and understanding of the Pounds. Through this work, we perceive the importance of teaching Libras in schools as the first language of the deaf, confirming that the earlier children have access to this learning, the better their development.

Keywords: Communication. Hearing deficiency. Teaching and learning process. Libras.

\section{CONSIDERAÇÕES INICIAIS}

O objetivo básico da comunicação humana é alterar as relações originais entre o próprio organismo humano e o ambiente em que ele se encontra. Especificando mais: o objetivo básico é reduzir a probabilidade de que sejamos simplesmente um alvo das forças externas (como acontece quando nascemos, pois não temos 0 mínimo controle sobre a nossa conduta, sobre o comportamento dos outros, sobre o ambiente físico em que nos encontramos. Estamos à mercê de qualquer força interessada em nos influenciar: e nós mesmos somos impotentes para influenciar qualquer coisa ou pessoa intencionalmente) e aumentar a probabilidade de que nós mesmos exerçamos força.

(DAVID K. BERLO, 1982, p. 17)

A linguagem que se constrói na relação do homem com o meio social, envolve tudo que tem significado e não se restringe somente a uma única forma de comunicação, uma vez que ela está sempre presente no sujeito, mesmo quando ele não está intencionalmente se comunicando com alguém, constituindo-se assim, numa forma como o indivíduo percebe o mundo e a si próprio.

Nesse processo, alguns sujeitos enfrentam algumas dificuldades de comunicação. Dentre eles, os surdos, que passam por essa situação, como resultado da imposição das línguas orais, que são faladas pela grande maioria das comunidades. Vários pesquisadores defendem a comunicação dos surdos e a constituição dos seus pensamentos, pois eles podem executar perfeitamente 0 mesmo papel atribuído ao aparelho fonador (fala) por meio da Língua Brasileira de Sinais, doravante Libras. 
Nesse cenário, a Língua de Sinais aparece como importante veículo de interação social, que possibilita a inclusão do aluno surdo no ensino regular. Pode ser assim, como uma das maiores expressões da cultura surda na atualidade, fato que exige da sociedade e da escola, seu reconhecimento e valorização, com vistas ao alcance de direitos sociais e de acesso a cidadania. Skliar (1999, p. 12), discorre sobre isso, apontando duas questões importantes:

A imensa quantidade de surdos que está fora do sistema escolar e a
que foi excluída muito antes de terminar a sua educação básica,
obriga-nos a colocar dois tipos de reflexão. Primeiro: a educação
bilíngue não pode ser assimilada à escolarização bilíngue, isto é, não
se deve justificar somente como ideário pedagógico a ser
desenvolvido dentro das escolas. Em virtude desta primeira questão
é que se faz impostergável uma política de educação bilíngue, de
prática e de significações, que devem ser pensadas nos diferentes
contextos históricos e culturais. A segunda reflexão se orienta para
uma análise sobre a maneira através da qual a surdez - como
diferença - é construída e determinada nos projetos políticos e
pedagógicos atuais.

Essa reflexão nos remete ao modo como deve acontecer o ensino para os alunos surdos, garantindo a aprendizagem, tanto da língua oficial, quanto sua língua natural, cumprindo assim, uma inclusão social, como preveem os documentos oficiais $^{3}$ que norteiam uma proposta de Educação Inclusiva no século XXI.

Partindo disso, Silva (2001) afirma que as condições de aprendizagem da leitura e da escrita no processo de escolarização do surdo dependem, por via de regra, do modo pelo qual são encaradas suas dificuldades e as diferenças ocorridas

\footnotetext{
${ }^{3}$ A título de ilustração, citamos alguns desses documentos, conforme listagem feita por Oliveira; Lima (2016, p. 60-61):

i) a Convenção dos Direitos da Criança, adotada pela Assembleia Geral nas Nações Unidas em 20 de Novembro de 1989 e ratificada por Portugal em 21 de Setembro de 1990;

ii) a Declaração de Jomtien, elaborada no Conferência Mundial sobre Educação para Todos, realizada na cidade de Jomtien, na Tailândia, em 1990;

iii) a Cúpula Mundial das Crianças, ocorrida nos dias 29 e 30 de setembro de 1990, em Nova York;

iv) a Declaração de Salamanca, resultante da Conferência Mundial sobre Necessidades Educativas, realizada em Salamanca, Espanha, de 07 a 10 de junho de 1994;

v) a Carta para o Terceiro Milênio, escrita e aprovada no dia 9 de setembro de 1999, em Londres - Grã-Bretanha;

vi) a Convenção de Guatemala, resultante da Convenção Interamericana para a Eliminação de Todas as Formas de Discriminação Contra as Pessoas Portadoras de Deficiência, aprovada pelo Conselho Permanente na sessão realizada em de 28 de maio de 1999;

vii) a Declaração Internacional de Montreal, aprovada em 5 de junho de 2001 pelo Congresso Internacional e Sociedade Inclusiva, realizado em Montreal, Quebec, Canadá.
}

Cadernos Cajuína, V. 4, N. 1, 2019, p. 71 - 83.

ISSN: 2448-0916 
no processo educacional pelas instituições, levando-o a adquirir confiabilidade nas dificuldades encontradas. Na verdade, suas dificuldades, em qualquer disciplina, estão relacionadas à estrutura linguística pouco desenvolvida, repercutindo na sua educação de modo geral.

No caso das crianças, as surdas apresentam um método de aquisição diferente das crianças ouvintes, e assim, para os primeiros é necessária a construção de sinais visuais, enquanto os segundos podem absorver através da audição. Desse modo, neste trabalho, temos como objetivo analisar o processo de apropriação da Libras por uma criança com deficiência auditiva; identificar as contribuições do uso da Libras na aprendizagem do sujeito, bem como, apresentar as metodologias aplicadas no ensino da Língua de Sinais.

\section{PRÁTICAS COMUNICATIVAS E COMUNICAÇÃO HUMANA}

A comunicação é uma atividade constante em qualquer escala de vida do ser humano, sem a linguagem o homem não seria capaz de estabelecer relações sociais, nem tão pouco evoluir. Para que o ato de comunicação se concretize é necessário que o indivíduo domine um sistema linguístico e que as mensagens do falante pertençam ao código que utilizam. No dizer de Lacerda (1998, p. 38-39):

É pela linguagem e na linguagem que se podem construir conhecimentos. É aquilo que é dito, comentado, pensado pelo sujeito e pelo outro, nas diferentes situações, que faz com que os conceitos sejam generalizados, sejam relacionados, gerando um processo de construção de conhecimentos que vai interferir de maneira contundente nas novas experiências que este sujeito venha a ter. Ele se transforma através desses conhecimentos construídos, transforma seu modo de lidar com o mundo e com a cultura e essas experiências geram outras, num movimento contínuo de transformações e desenvolvimento. A mediação semiótica (mediação que se dá através dos sinais, dos signos e das palavras, etc.) é que permite também a incorporação do sujeito ao meio social e, como consequência, a apropriação deste.

É através da linguagem que o homem conhece o mundo que o cerca e constrói sistemas que transmitem sentidos e significados. E o desenvolvimento dessa linguagem só depende de condições ambientais. Um exemplo disso é a criança que pode tornar-se falante nativo de qualquer língua. Qual língua aprenderá 
é uma questão que depende dos modelos que tiver à sua volta. A respeito da comunicação, Sánchez (1990, p. 17) diz:

A comunicação humana é essencialmente diferente e superior a toda outra forma de comunicação conhecida. Todos os seres humanos nascem com mecanismo de linguagem específicos da espécie, e todos desenvolvem normalmente, independentes de qualquer fator racial, social ou cultural.

No Brasil, o processo de comunicação acontece de forma bastante dinâmica, uma vez que o seu sistema linguístico é muito complexo - a Língua Portuguesa, geralmente estudada do ponto de vista estruturalista e gramatical, desconsiderando-se as situações de interação social, onde, de fato, a língua assume sua vivacidade. Embora as pessoas partilhem da mesma língua no meio falante, não partilham das mesmas necessidades qualitativas e quantitativamente, enquanto alguém está com fome, outro está com sede, outro com sono. Isso gera comportamentos diferentes no espaço e no tempo dentro de determinadas personalidades (OLIVEIRA, 2002).

Oliveira (2002) afirma ainda que o ser humano é meio confuso e falso quando fala; e meio paranoico quando escuta. Ao falar não tem o cuidado de ser claro, conciso e sincero. Ao escutar não consegue se ater somente ao que foi falado; tem mania de pressupor e interpretar de acordo com seus valores o que outra pessoa disse. Age como se sua cabeça estivesse fixada no pescoço de outra pessoa; quando na verdade cada coisa deve ser interpretada com seu próprio valor.

No Brasil, além do Português, existem ainda duas línguas: Urubus Kapur, falada por uma tribo de índios da Amazônia e a Libras, falada pelas comunidades surdas, conforme discutimos a seguir.

\section{O QUE É LIBRAS?}

A Libras é a Língua Brasileira de Sinais, desenvolvida e utilizada pelas comunidades surdas. É uma língua de modalidade gestual-visual, porque, utiliza como canal de comunicação, os movimentos e as expressões percebidos pela visão e formadas a partir da combinação de movimentos de mãos em pontos e espaços chamados parâmetros. 
A LIBRAS (Língua Brasileira de Sinais) é a língua natural da comunidade surda utilizada no Brasil com sua estrutura e gramática própria que é utilizada para a comunicação entre surdos e ouvintes. É reconhecida oficialmente pelo governo Brasileiro através da Lei 10.436/2002. É uma língua de modalidade gestual - visual que utiliza como canal ou meio da comunicação, movimentos gestuais e, expressões faciais que são percebidos pela visão. É a melhor forma de interação entre pessoas surdas, nas escolas, entre professores, alunos, colegas e no convívio social. (CARVALHO; CASTRO, 2005, p. 28)

A Libras, assim, como as outras línguas de sinais de outros países, apresenta organização, estrutura formal e gramatical própria. Os parâmetros que compõe os sinais como configuração de mãos e seus movimentos e sua localização em relação ao corpo do sujeito podem ser combinadas a partir de diversos movimentos, a fim de expressar diferentes significados. Exemplo: o dedo indicador em "D" sobre a boca com expressão facial calma e serena, significa "silêncio"; o mesmo sinal feito rapidamente e com expressão de zangado significa uma severa ordem "cale a boca"! (VALVERDE, 1990)

Sendo utilizada por comunidades surdas no Brasil, o Português deve ser aprendido, mas é considerado pelos defensores da Libras, como segunda língua. Nesse ponto, para Goldfeld (1997, p. 39),

O conceito mais importante que a filosofia Bilíngue traz é de que os
surdos formam uma comunidade, com cultura e língua próprias. A
noção de que o surdo deve, a todo custo, tentar aprender a
modalidade oral da língua para poder se aproximar o máximo
possível do padrão de normalidade é rejeitada por esta filosofia. Isto
não significa que a aprendizagem da língua oral não seja importante
para o surdo, ao contrário, este aprendizado é bastante desejado
mas não é percebido como o único objetivo educacional do surdo
nem como uma possibilidade de minimizar as diferenças causadas
pela surdez.

Segundo Valverde (1990), a Libras não dispõe de sinais para artigos, para a maior parte das preposições e das conjunções do Português, já que o significado expresso por tais elementos está contido no próprio sinal. Os modos e tempos verbais, assim como os prefixos e sufixos, são produzidos por movimentos de mãos no espaço. Por exemplo: em português dizemos: "Eu fui para casa de carro". Em Libras, a mesma frase ficaria assim: "Eu ir casa carro." 
Klima; Bellugi (1979) destacam que a Língua de Sinais apresenta uma característica formal e icônica. Por formal, os autores entendem que existem regras que regem a formação dos sinais, bem como a sintaxe que é própria e característica, com flexões que são expressas através da expressão corporo-facial. Por icônica, entende-se como a relação básica direta entre sinal e objeto representado, que se dá quando o sinal é criado.

Klima; Bellugi (1979) afirmam ainda que se a Língua de Sinais fosse apenas icônica, ouvintes normais a entenderiam sem problemas, o que corresponde à realidade. Esta língua apresenta-se por meio da associação de sinais que remetem a imagem ou ícones, representando geralmente, elementos mais concretos; e por símbolos arbitrários, designando os elementos de natureza mais abstrata.

Os usuários da Libras utilizam-se de um alfabeto digital, baseado nas letras do alfabeto comum (de $\mathrm{A}$ a $\mathrm{Z}$ ), que permite a soletração e a tradução para o Português.

Para Quadros (1997), a Libras é adquirida pelos surdos brasileiros de forma natural, mediante contato com sinalizadores, consequentemente, deve ser sua primeira língua. A aquisição dessa língua precisa ser assegurada para realizar um trabalho sistemático com a segunda língua, considerando a realidade do ensino formal. A necessidade formal do ensino de Língua Portuguesa evidencia que essa língua é, por excelência, uma segunda língua para a pessoa surda.

Nesse sentido, conhecer o desenvolvimento da linguagem e conhecer as condições do processo de aquisição da Libras, considerando sua legitimidade social, deve ser o ponto de partida para qualquer profissional que objetive trabalhar com surdos. É importante ter o conhecimento não apenas da língua em questão, mas também, de estratégias sobre como ensinar, para que a aprendizagem não aconteça de forma inadequada, sem respeitar ou valorizar as condições de cada sujeito da aprendizagem, como se verifica neste estudo, ao estudar o processo de ensino e aprendizagem da Libras por uma criança com deficiência auditiva

\section{PROCEDIMENTOS METODOLÓGICOS}

Do ponto de vista metodológico, esta pesquisa foi construída a partir de um estudo de caso, por meio do qual se acompanhou a condução do processo de ensino e aprendizagem da Libras por uma criança com deficiência auditiva. O estudo 
foi realizado com base em teóricos, como: Castro; Carvalho (2005), Goldfeld (1997), Oliveira (2002), Quadros (1997), Silva (2001), entre outros.

Realizamos o estudo no período de quatorze semanas, através de observações e atividades práticas para verificação do processo de apropriação da Libras. O local escolhido para a coleta de dados da pesquisa de campo foi uma escola da rede estadual de ensino localizada na zona Sul de Teresina (PI). O local foi escolhido por se tratar de uma escola que atende alunos surdos de outras escolas na sala de Atendimento Educacional Especializado (AEE).

O trabalho foi desenvolvido no segundo semestre de 2014, em uma sala de recursos multifuncionais, com um sujeito que se comunicava através de gestos. $\mathrm{E}$ para a coleta de dados, utilizamos como instrumentos, a observação e aplicação de atividades a uma criança com deficiência auditiva, que estudava em uma creche pela manhã e no período da tarde, frequentava a referida sala, ou seja, no turno inverso da escolarização regular.

É Importante ressaltar que, na ocasião da coleta de dados, os sujeitos envolvidos no processo (os pais da criança) concordaram livremente em contribuir com a pesquisa, através de assinatura de Termo de Consentimento Livre e Esclarecido (TCLE), em duas vias, sendo uma sua, e a outra, dos pesquisadores responsáveis; e Termo de Assentimento (TA) para o trabalho com a criança, de modo que assim, foram resguardados seus direitos e mantida a preocupação, o zelo e o sigilo com a imagem dos colaboradores da pesquisa.

\section{A APROPRIAÇÃO DA LIBRAS POR UMA CRIANÇA COM DEFICIÊNCIA AUDITIVA: O ESTUDO DE CASO}

Pelo período de quatro (04) meses realizamos um estudo de caso com uma criança com deficiência auditiva, a fim de observar e analisar sua capacidade de apropriação da Libras.

O sujeito em estudo era uma criança de cinco (05) anos de idade, do sexo feminino, filha de pais ouvintes. Três meses após o casamento, supondo que o esposo havia se curado de uma meningite, a mãe engravidou. Durante o período de gravidez, a mesma não teve nenhum problema de saúde, também não fumava, nem bebia álcool. O parto ocorreu sem complicações e até os oito meses de idade, a mãe acreditava que a filha não tivesse nenhum problema, foi quando começou a 
perceber que a filha não respondia aos seus chamados e nem se incomodava com barulhos.

A família, preocupada, procurou ajuda médica e segundo a mãe, o primeiro médico a examinar a menina, atestou que ela não tinha nenhum problema, justificando ainda, que algumas crianças demoram mais tempo que as outras para falar. Não satisfeitos com o diagnóstico, os pais procuraram outro profissional, que através de um exame de audiometria, diagnosticou a deficiência auditiva.

A partir de então, a família passou a questionar quais seriam as possíveis causas da deficiência da criança e chegaram à conclusão de que era consequência da doença do pai, já que na família não há nenhum outro caso de surdez.

No início do ano de 2014, a mãe, separada do pai e já casada com outra pessoa e com o segundo filho ouvinte, matriculou a criança em uma creche no turno manhã e à tarde em uma sala de recursos multifuncionais. Apesar de frequentar a escola pela primeira vez e estar há pouco tempo na sala de recursos, observamos seus avanços.

Para aplicação das atividades elaboramos planos de aula que contemplavam a Libras, além disso, observamos o comportamento da criança nos diversos espaços da escola (sala de aula, refeitório, pátio etc.). O interesse na observação consistia em verificar como ela se comunicava com as outras crianças e qual o significado dos gestos por ela utilizados na comunicação.

Percebemos que ela utilizava poucos gestos e não se socializava. Enquanto estava fora da sala de aula preferia a companhia dos professores. Nessa oportunidade, proporcionamos a interação com os demais, por meio do ensino da Língua de Sinais.

O Quadro 01, a seguir, mostra os sinais que foram ensinados e aprendidos pela criança no decorrer do estudo.

Quadro 01: Sinais ensinados

\begin{tabular}{|c|l|c|}
\hline $\begin{array}{c}\text { TIPOS DE } \\
\text { SINAIS }\end{array}$ & \multicolumn{1}{|c|}{ SINAIS ENSINADOS } & $\begin{array}{c}\text { QUANTIDADE DE SINAIS } \\
\text { APREDNDIDOS }\end{array}$ \\
\hline CORES & Vermelho, amarelo, azul, verde, preto. & TODOS \\
\hline ANIMAIS & $\begin{array}{l}\text { Cachorro, gato, coelho, cavalo, boi, } \\
\text { borboleta, galinha. }\end{array}$ & TODOS \\
\hline FRUTAS & Banana, laranja, caju, melancia. & Banana, laranja, melancia. \\
\hline
\end{tabular}




\begin{tabular}{|c|c|c|}
\hline PESSOAS & $\begin{array}{l}\text { Homem, mulher, menino, menina, pai, } \\
\text { mãe, irmão. }\end{array}$ & TODOS \\
\hline PRÉDIOS & Casa, escola, prédio. & Casa \\
\hline DIVERSOS & $\begin{array}{l}\text { Amigo, feio, bonito, banheiro, comer, } \\
\text { beber, água, igual, diferente, árvore. }\end{array}$ & TODOS \\
\hline TRANSPORTE & $\begin{array}{l}\text { Bicicleta, moto, carro, ônibus, avião, } \\
\text { trem, barco. }\end{array}$ & $\begin{array}{l}\text { Bicicleta, moto, carro, ônibus, } \\
\text { avião. }\end{array}$ \\
\hline LETRAS & $A, B, C, D, E, F, I, O, U, R, N$ & TODOS \\
\hline
\end{tabular}

Fonte: Dos autores (2014)

Na primeira semana, não houve o ensino da Libras, apenas a observação das formas e gestos que o sujeito utilizava para se comunicar, como também inserila no contexto escolar, colocando-a na fila com as outras crianças para receber o lanche, colocar prato e copo no lugar indicado, sem nenhum tratamento diferenciado para que não se sentisse diferente dos outros.

$\mathrm{Na}$ segunda semana, trabalhamos os sinais. A princípio, usamos alguns sinais básicos como: 'água', 'comer', 'banheiro', 'professora', 'mãe', 'pai' e 'irmão'. Desses sinais verificamos a aprendizagem do 'comer', 'beber', 'mãe', entre outros, embora não tenha havido demonstração de aprendizado.

$\mathrm{Na}$ terceira semana, inserimos as cores 'vermelha', 'verde', 'preta', 'azul' e 'amarela'. $O$ ensino das cores surgiu a partir do interesse da criança por um jogo. $O$ planejamento para esta semana seria trabalhar as letras do nome da criança. Ao observar a mesma manuseando o jogo, percebemos que esta começou a separar as peças por cores e formas, e a partir daí, foi feito outro plano de ensino para o trabalho com as cores. No decorrer da semana, trabalhamos outros objetos e figuras que ilustravam as cores em estudo.

$\mathrm{Na}$ quarta e quinta semanas, fizemos um trabalho de revisão dos sinais estudados: 'comer', 'água', 'pai', 'mãe', 'irmão', as cores 'vermelho', 'azul', 'verde', 'amarelo' e 'preto'. É importante enfatizar que nas primeiras aulas, não foi fácil chamar a atenção da aluna, pois não estava acostumada a manter-se no mesmo espaço, longe da família por tanto tempo. Em alguns momentos, precisamos parar e refazer os planos de aula, pois surgiram fatos interessantes a serem aproveitados para Ihe ensinar, como por exemplo, mostrar uma imagem porque seu interesse se voltava para outros objetos. 
Na sexta semana, ainda aproveitando o ábaco, percebemos que podíamos trabalhar os sinais matemáticos 'igual' e 'diferente', já que as peças do jogo não eram iguais. Nessa mesma semana introduzimos também, os sinais das letras A e $\mathrm{E}$; sempre tendo o cuidado de mandar atividades para casa, para que o sujeito colocasse em prática aquilo que the foi ensinado.

$\mathrm{Na}$ sétima semana, trabalhamos as vogais $\mathrm{A}, \mathrm{E}, \mathrm{I}$ e $\mathrm{O}$. Nessa semana, proporcionamos à criança, o envolvimento em trabalhos de pinturas, colagens e escrita com as letras e os sinais das mesmas.

$\mathrm{Na}$ oitava semana, ensinamos os sinais: 'bonito', 'feio' e 'amigo'. Para o sinal 'amigo', a criança sentiu certa dificuldade de entender, haja vista, que não existia uma gravura que especificasse o sinal de forma clara, então começamos a apresentar algumas pessoas para a criança e mostrar-lhe o sinal, a princípio ela não entendia, mas com a repetição, houve o aprendizado.

$\mathrm{Na}$ nona semana, fizemos uma revisão do que havia sido ensinado. A cada dia eram feitas atividades voltadas para sinais específicos. Na décima semana, como já havia aprendido os sinais das vogais $A, E, I, O$, introduzimos a vogal $U$, e as letras $\mathrm{B}, \mathrm{C}, \mathrm{D}, \mathrm{N}$ e R. O objetivo era que o sujeito reconhecesse as letras e os sinais que formavam seu nome.

$\mathrm{Na}$ décima primeira semana, ensinamos sinais de alguns meios de transportes como 'carro', 'ônibus', 'bicicleta', 'barco', 'avião', 'trem', 'moto'. O ensino desses sinais foi fundamental para que a criança conhecesse as situações que são vivenciadas constantemente pela família, como pegar o ônibus, andar de bicicleta etc. Na décima segunda semana, continuamos com o ensino dos sinais dos meios de transportes, mencionados acima.

$\mathrm{Na}$ décima terceira semana, ensinamos os sinais de alguns animais: 'cachorro', 'cavalo', 'gato', 'coelho', 'boi', 'galinha', 'borboleta'. Na décima quarta semana, trabalhamos as frutas: 'banana', 'laranja', 'melancia' e 'caju'. O importante ao ensinar esses sinais foi trazer para seu conhecimento objetos, animais e lugares que fossem conhecidos no seu contexto para que o aprendizado acontecesse de acordo com a realidade em que o sujeito estava inserido.

\section{CONSIDERAÇÕES FINAIS}


A partir dos estudos e dados obtidos com a pesquisa podemos observar como o surdo constrói seu conhecimento no espaço escolar, em que o professor é seu mediador. De modo que as reflexões sobre os dados analisados levam-nos a afirmar que a Libras é a via natural para o surdo organizar e adquirir conhecimentos.

Nossa preocupação, como professores pesquisadores, era de facilitar o aprendizado, servindo-se de material concreto para que o sujeito compreendesse $o$ significado do mundo oportunizando, principalmente a comunicação do indivíduo com o mundo.

O trabalho com a Libras trouxe a certeza de que muito ainda precisa ser feito para que o surdo sinta-se incluído no processo educativo. Nesse sentido, esperamos que 0 trabalho apresentado venha a contribuir para um melhor atendimento educacional ao indivíduo surdo e possibilite uma sensibilização sobre a "escola que temos", a "escola que queremos" e a "escola que é possível" (SILVA, 2001, p. 95).

Essas reflexões enfatizam a necessidade de repensar a realidade do ensino para surdos nas escolas regulares. É importante mencionar que várias situações poderiam ser ainda discutidas, tendo em vista a educação do surdo, mas as questões demandariam outro tema e outras pesquisas para muitos estudiosos.

\section{REFERÊNCIAS}

CASTRO, Alberto Rainhade; CARVALHO, Ilza Silva de. Comunicação por Língua Brasileira de Sinais: livro básico. Brasília: Editora SENAC, 2005.

GOLDFELD, Márcia. A criança surda: linguagem e cognição numa perspectiva sócio-interacionista. São Paulo: Plexus, 1997.

K. BERLO, David. O processo de comunicação: introdução a teoria e à prática. São Paulo: Martins Fontes, 1982.

KLIMA, E.S.; BELLUGI, U. The signs of language. Cambridge: Harvard University Press, 1979.

LACERDA, C. B. F. A prática fonoaudiológica frente às diferentes concepções de linguagem. Espaço, oo10, dez/1998, p. 30-40.

OLIVEIRA, Maria Helena de; LIMA, Francisco Renato. A educação especial no contexto da sociedade inclusiva: construindo sentidos sobre a aprendizagem de crianças com deficiências. Cadernos Cajuína, v. 1, no 2, p. 59-70, 2016. Disponível 
em: < http://cadernoscajuina.pro.br/revistas/index.php/cadcajuina/article/view/16/24 >. Acesso em: 08 ago. 2018.

OLIVEIRA, Rui de. Neurolinguistica e o aprendizado da linguagem. Catanduva: Respel, 2002.

QUADROS, Ronice Muller de. Educação de surdez: aquisição da linguagem. Porto Alegre. Artimed, 1997.

SÁNCHEZ, C. M. La increible y triste história de la sordera. Caracas: Impresión Ceprosord. 1990.

SKLIAR, C. Atualidade da educação bilíngue para surdos. Porto Alegre: Mediação, 1999.

SILVA, Marília da Piedade Marinho. A construção da escrita do aluno surdo. São Paulo: Plexus, 2001.

VALVERDE, F. M. Língua Brasileira de Sinais - LIBRAS: a visão de um professor de sinais, surdo adulto. Rio de Janeiro. Cultura Médica, 1990. 